\title{
Socioambientalismo em Imagem
}

\author{
Manuel Munhoz Caleiro' \\ Curador
}

Considerando que a linguagem fotográfica é uma das formas de compreensão das diferentes maneiras de interação entre ohumano e os demais elementos da natureza, o grupo de pesquisa em Direito Socioambiental da Pontifícia Universidade Católica do Paraná (PUCPR), em parceria com a Rede de Imagem, Direito e Meio Ambiente (RIDMA), realizou até o momento duas mostras fotográficas como eventos paralelos ao Congresso Brasileiro de Direito Socioambiental, em suas edições de número IV (2013) e V (2015). Em ambas as ocasiões as mostras foram realizadas no mesmo espaço onde ocorreram as discussões, que contaram com participação de integrantes da academia e de movimentos sociais, possibilitandouma interação entre os debates e as imagens expostas. Além da exposição física nos eventos, fotografias de cada edição da mostra são expostas permanentemente no endereço www.direitosocioambiental.com.br.

1 Doutorando em Direito Socioambiental pela Pontifícia Universidade do Paraná (PUCPR). 


\section{Isabella Cristina Lunelli (UFSC)}

\section{isalunelli@hotmail.com}

A vida cotidiana de artesãs Aymaras Peruanas é retratada sobre totoras, num território flutuante não reconhecido sobre as águas do Titicaca. Sobreviventes e resistentes Incas, enfrentando contaminações do extrativismo mineral e de esgoto, seguem cultivando formas ancestrais de uso e conservação dos recursos naturais. Ilha de Uros, Lago Titicaca, Puno/Peru. 


\section{FOTOGRAFIAS}

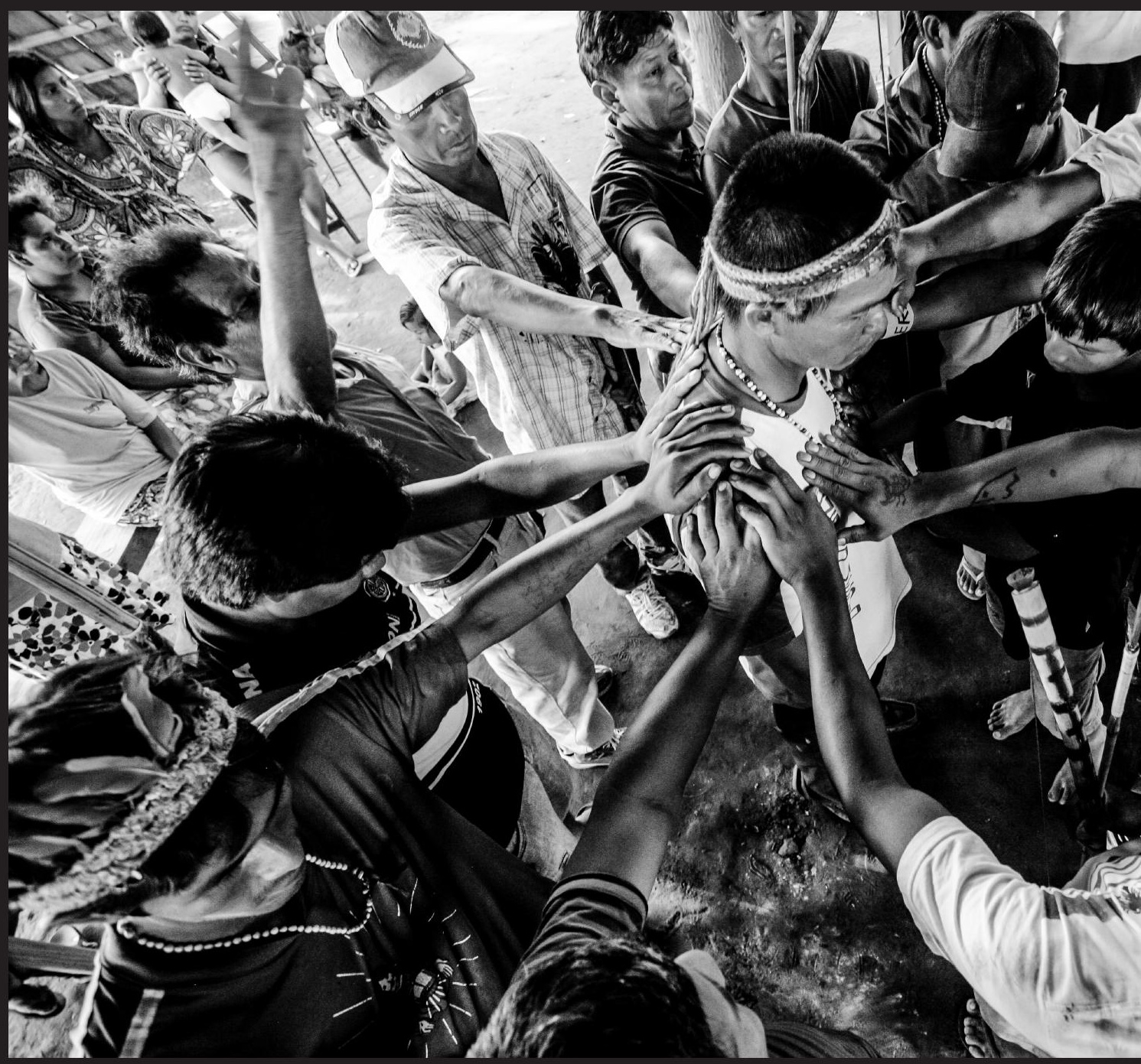




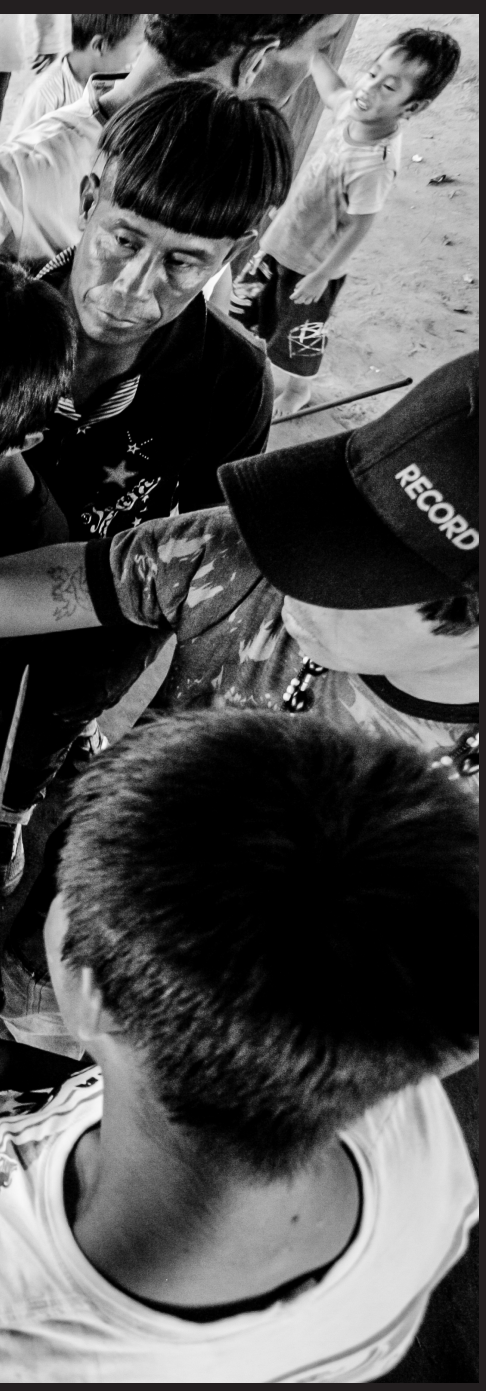

\section{Paulo Humberto Porto Borges (UNIOESTE)}

pauloportoborges@gmail.com

Cacique Libório sendo abençoado por demais lideranças guarani em reunião na Tekoha Araguaju, no município de Terra Roxa, Paraná. Em pauta a luta territorial e a demarcação das áreas tradicionais. 


\section{FOTOGRAFIAS}

\section{Manuel Caleiro (PUCPR)}

manuelcaleiro@gmail.com

Criança Guarani caminha rumo ao cemitério na Tekoha Mirim, oeste paranaense, onde no dia anterior foi sepultado um jovem Guarani que cometeu suicídio. A taxa de suicídio entre jovens da etnia é seis vezes maior que a média nacional.

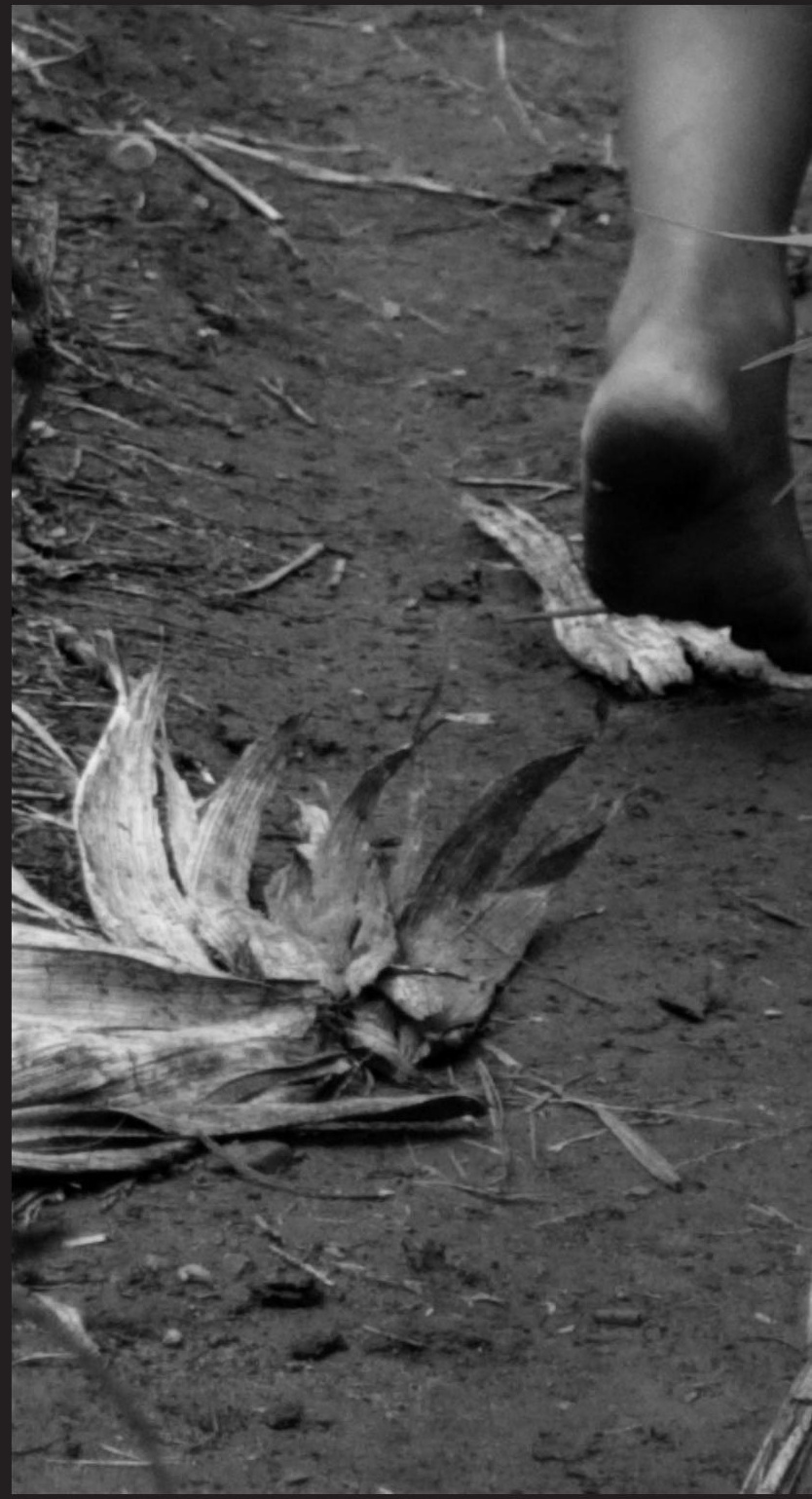


IPDMS - Instituto de Pesquisa Direitos e Movimentos Sociais

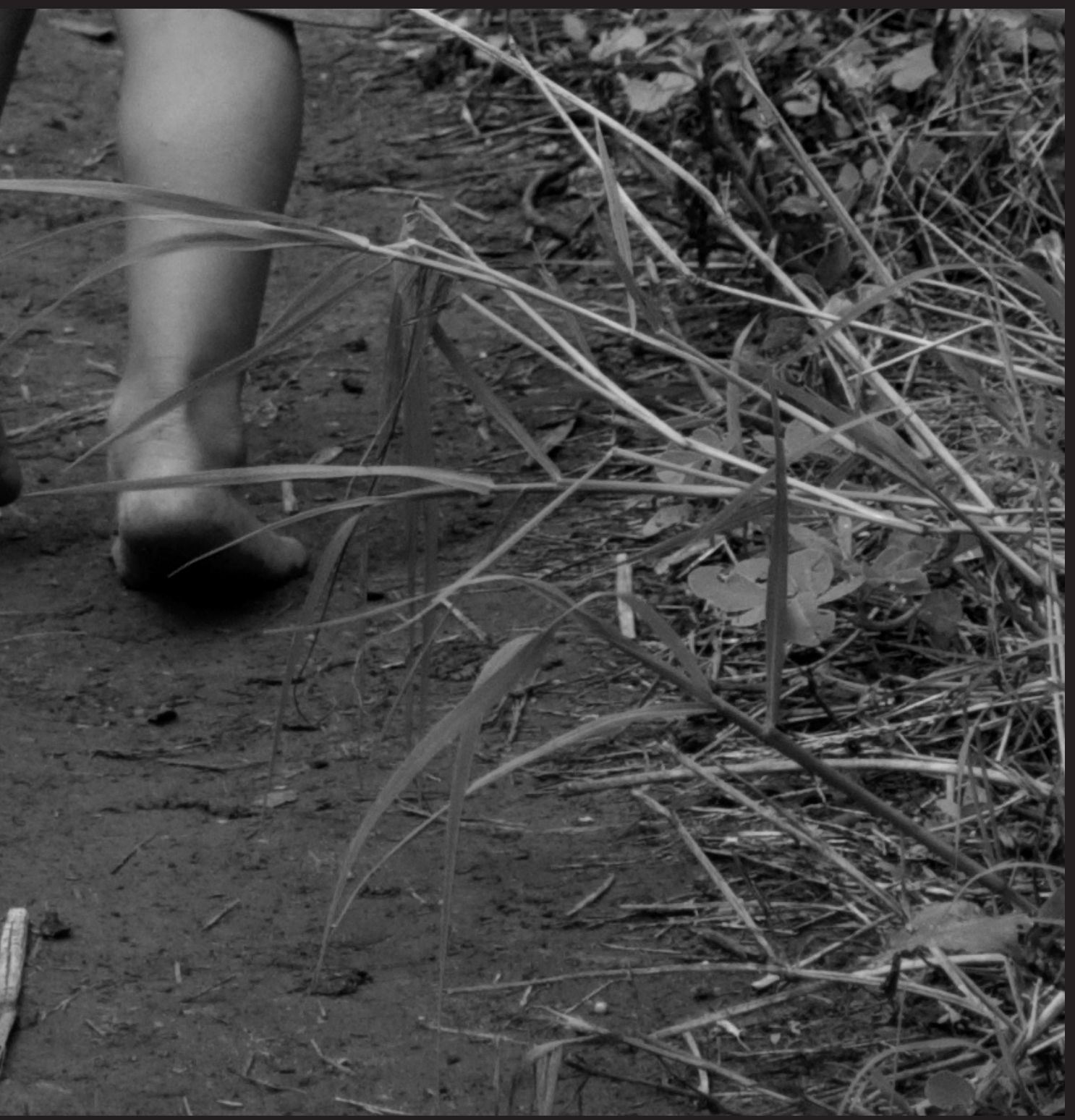




\section{FOTOGRAFIAS}

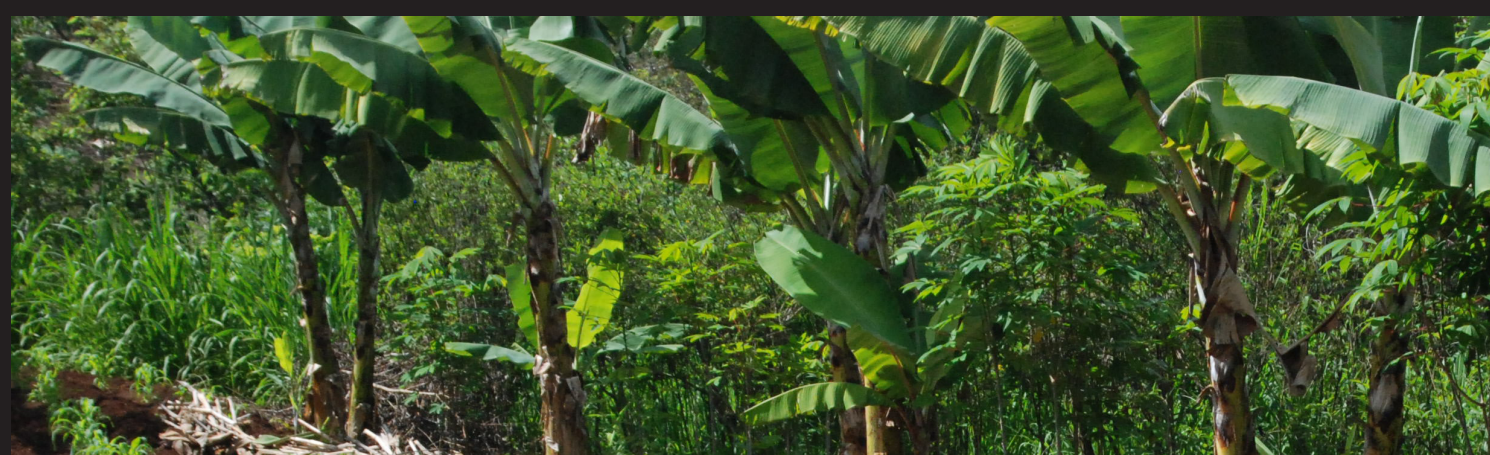

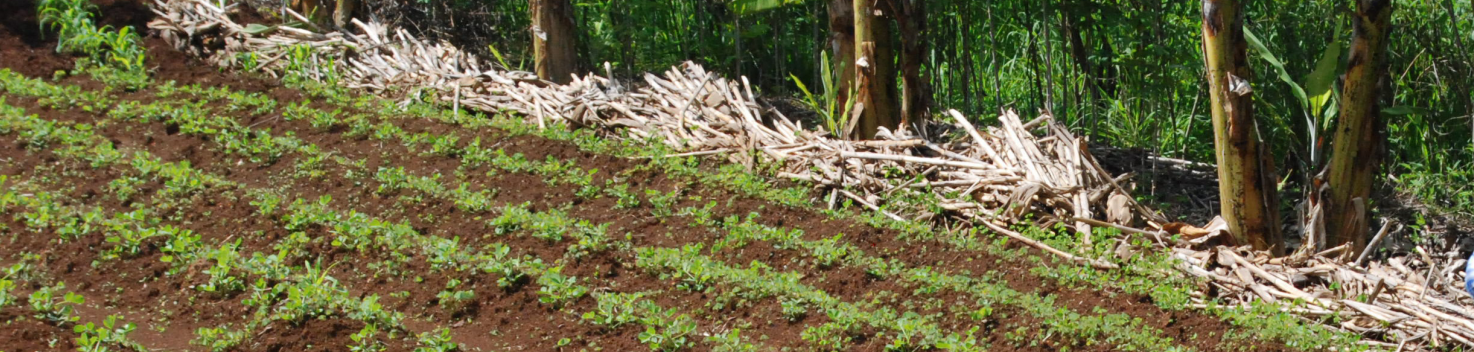

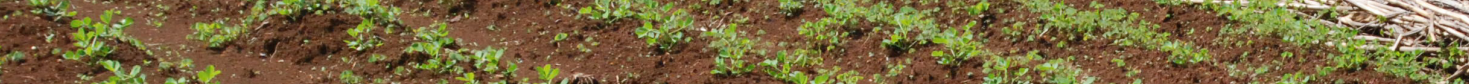

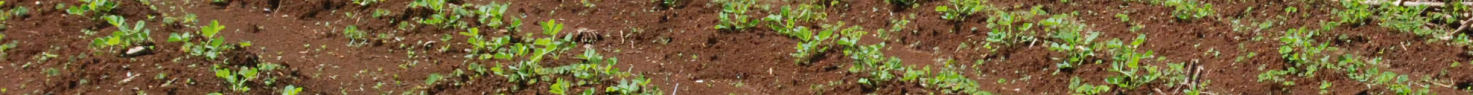

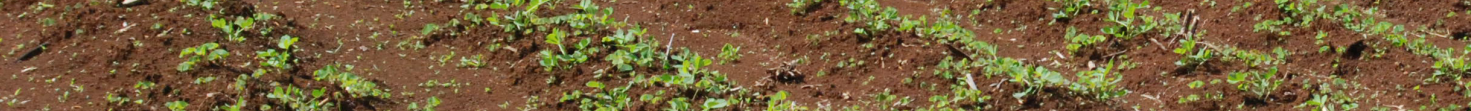

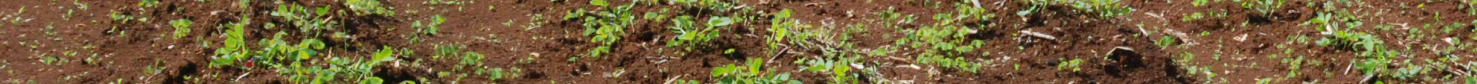

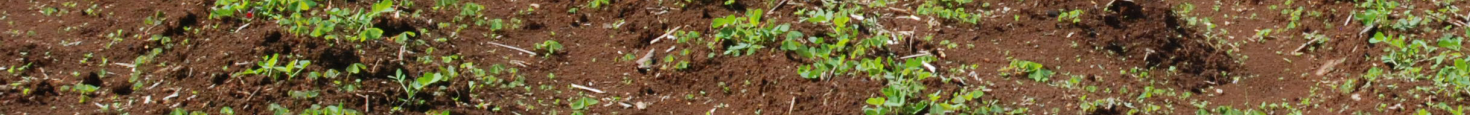

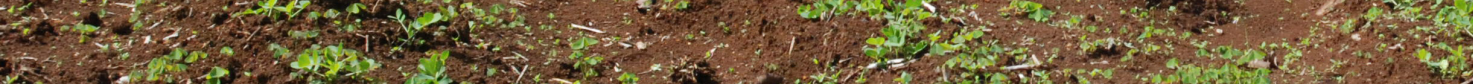

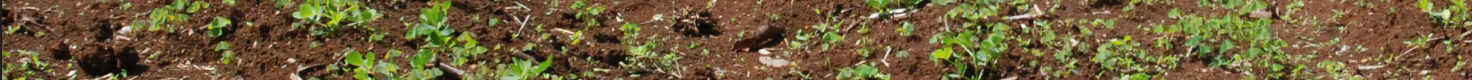

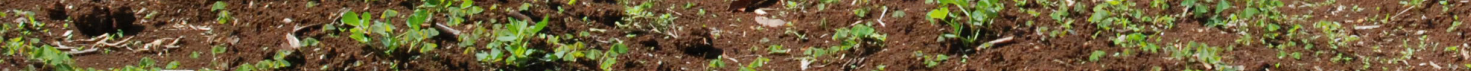
4 -

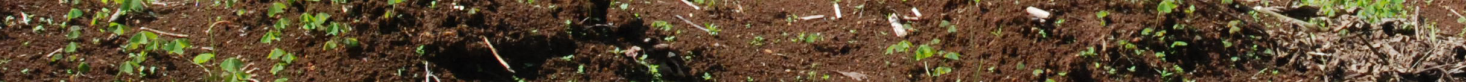

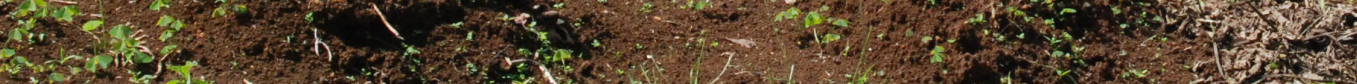

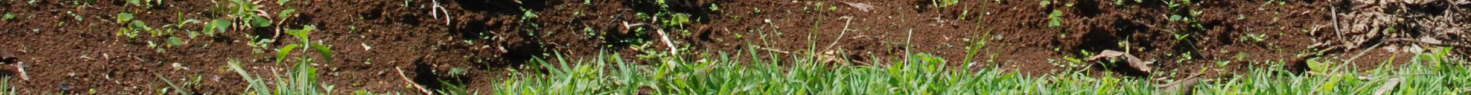
W. 1.5.

35-

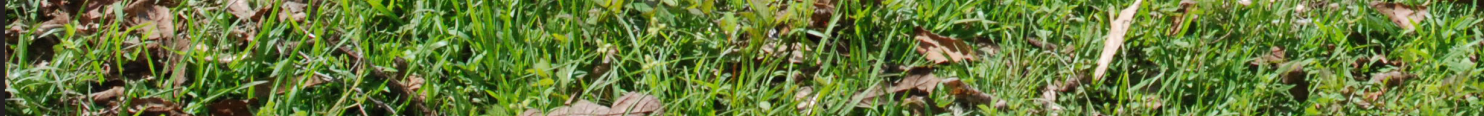
20.6. 


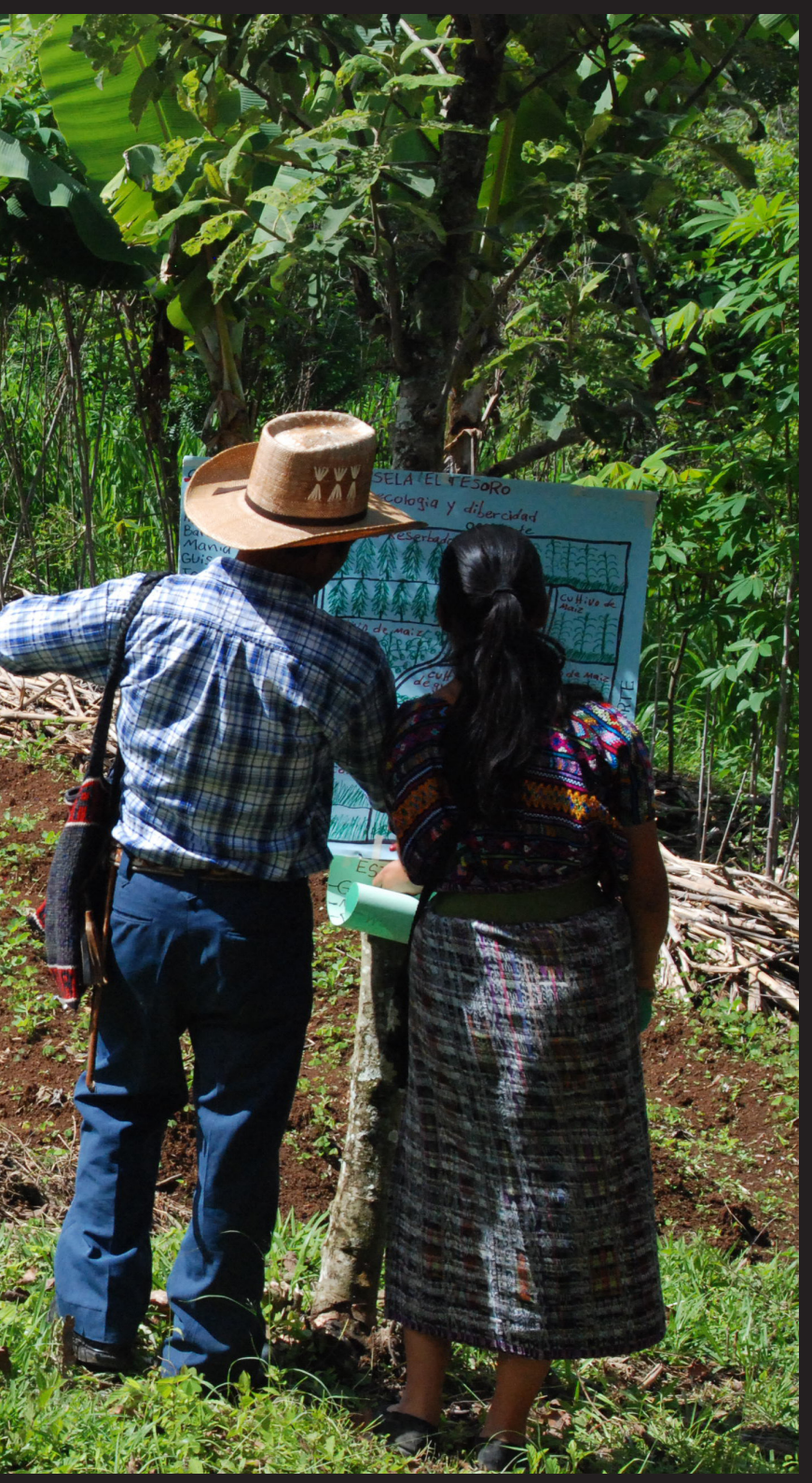

\section{Danielle de Ouro Mamed (PUCPR)}

mamed.danielle@gmail.com

Casal guatemalteco explica croqui de distribuição de cultivo agroecológico que atende a todas as necessidades da família. Estado de Chimaltenango, Município de San Martín de Jilotepec,

Guatemala. 


\section{FOTOGRAFIAS}

\section{Liana Amin Lima da Silva (PUCPR)}

\section{lianalima@gmail.com}

Menina assiste pela janela à oficina do Conselho Comunitário do Alto Atrato sobre a Lei 70/ 1993 e o debate sobre a recuperação da autonomia territorial das comunidades negras no Pós-conflito. Comunidad La Playa, Chocó, Colombia.

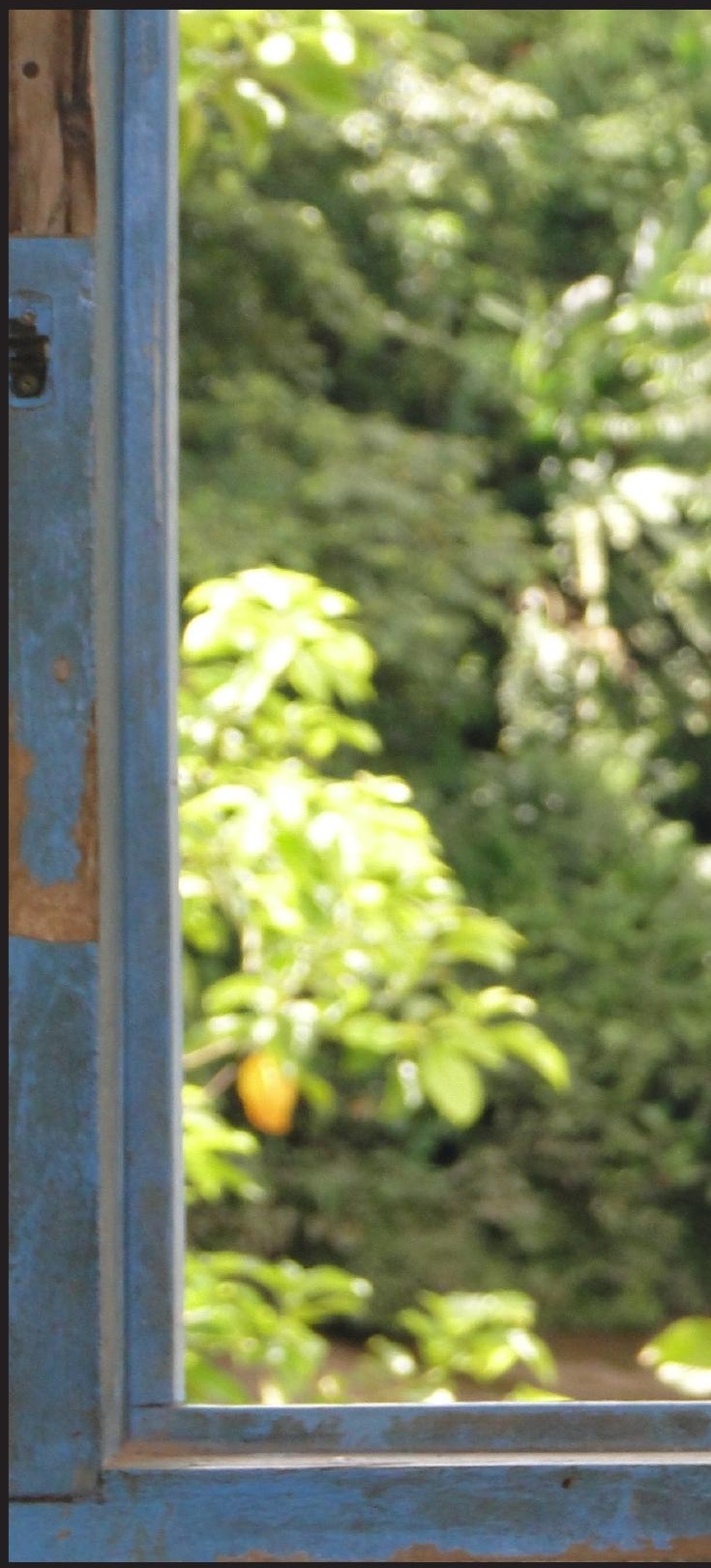




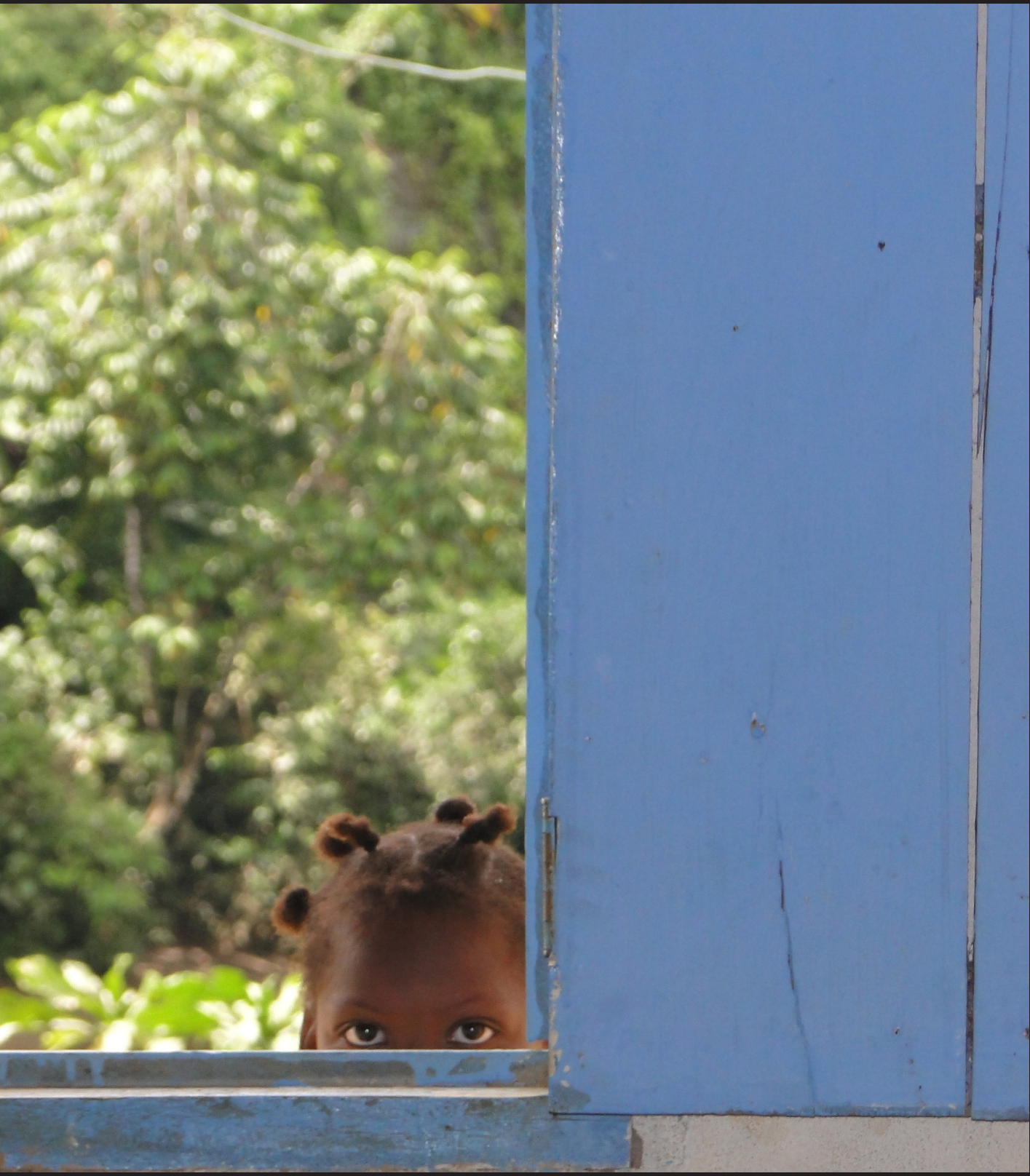




\section{FOTOGRAFIAS}

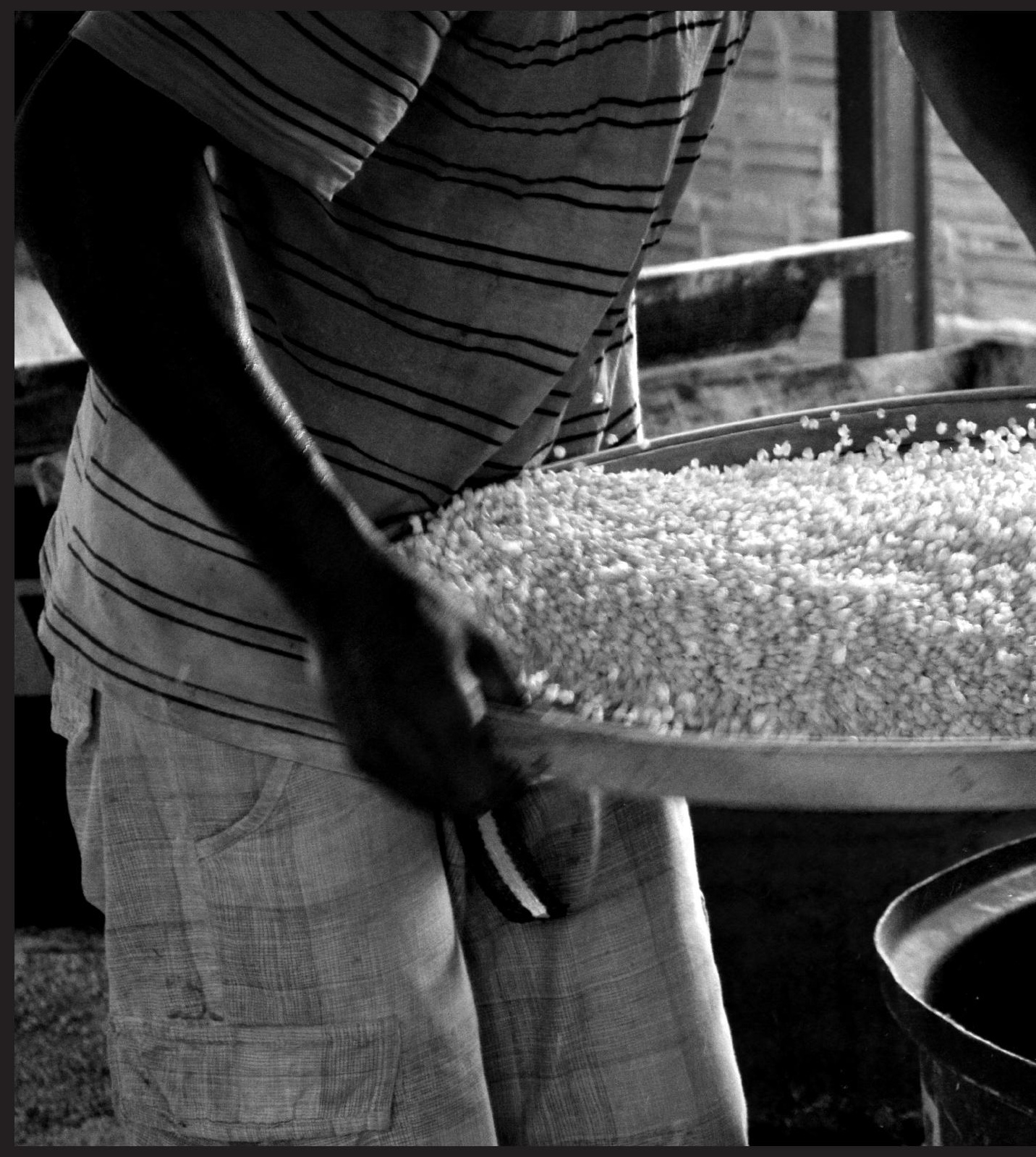




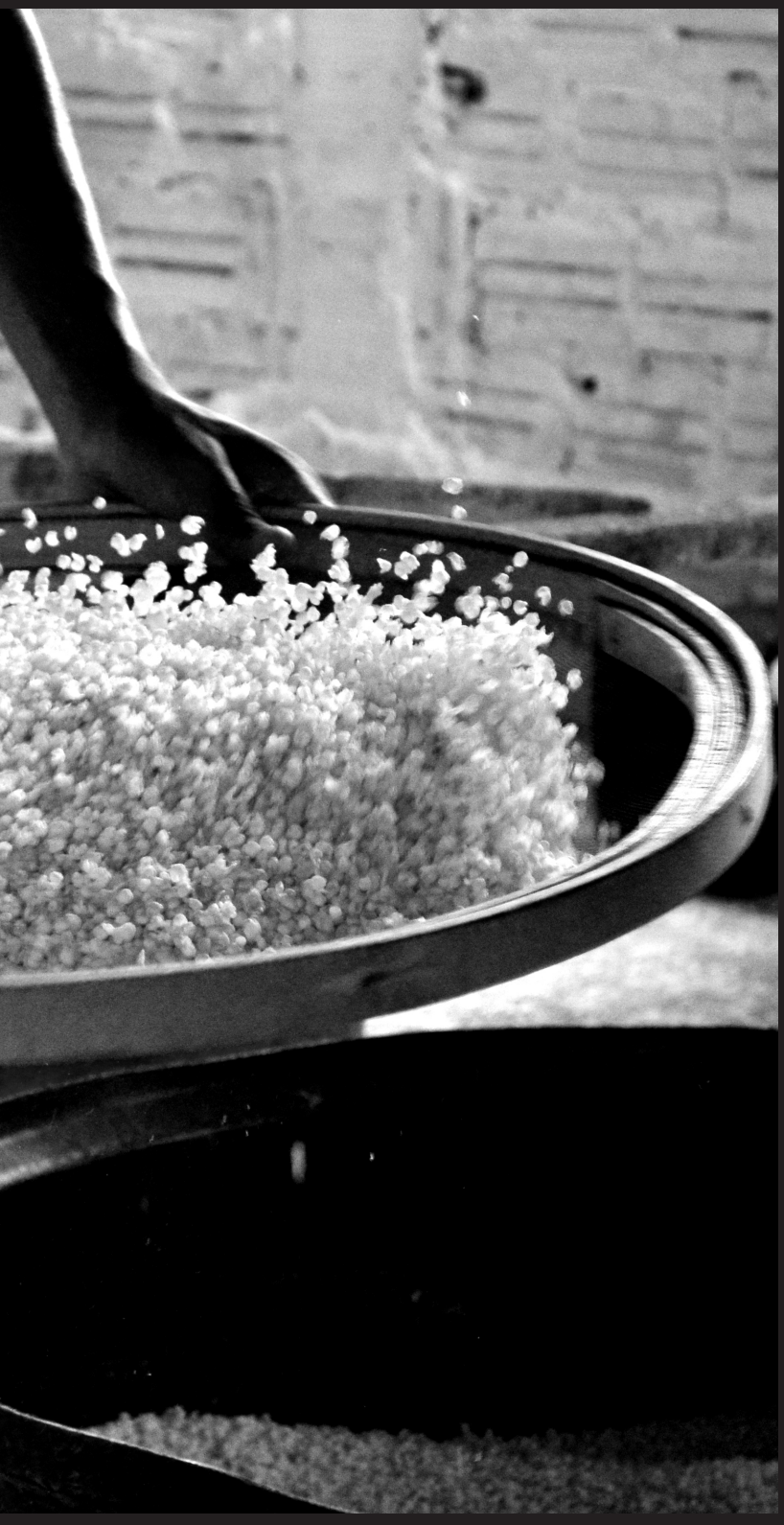

\section{Bruna Balbi Gonçalves (PUCPR)}

bruna.balbi@gmail.com

Retomada da produção de tapioca após a cheia do rio Madeira, que submergiu as casas do bairro Triângulo, à $5 \mathrm{~km}$ da usina hidrelétrica de Santo Antônio, Porto Velho/RO. 